\title{
Conjugational Fertility and Location of Chloramphenicol Biosynthesis Genes on the Chromosomal Linkage Map of Streptomyces venezuelae
}

\author{
By J. L. DOULL,${ }^{1}+$ S. VATS, ${ }^{2}$ M. CHALICIOPOULOS, ${ }^{2}$ C. STUTTARD,${ }^{1 *}$ \\ K. WONG ${ }^{1} \ddagger$ AND L. C. VINING ${ }^{2}$ \\ Departments of Microbiolog $y^{1}$ and Biology ${ }^{2}$, Dalhousie University, Halifax, Nova Scotia, \\ Canada $\mathrm{B} 3 \mathrm{H} 4 \mathrm{H} 7$
}

(Received 2 October 1985)

\begin{abstract}
In Streptomyces venezuelae fertility, defined as chromosomal gene recombination, was enhanced over 1000-fold when one parent in a biparental conjugational cross lacked the physicallyundetected plasmid SVP1, as compared with crosses in which both parents carried SVP1. The existence of SVP1 and at least two other fertility plasmids, SVP2 and SVP3, was detected in $S$. venezuelae by 'lethal zygosis' elicited by a plasmid-plus mycelium in contact with a plasmidminus mycelium. Conjugational crosses were used to construct a linkage map of $S$. venezuelae which was highly consistent with the map of analogous loci in $S$. coelicolor A3(2). A cluster of genes governing chloramphenicol biosynthesis was located near arg, cys and $p d x B$ genes at a position roughly equivalent to the 1-2 o'clock region of the $S$. coelicolor A3(2) map.
\end{abstract}

\section{INTRODUCTION}

In previous work with chloramphenicol-producing $\left(\mathrm{Cml}^{+}\right)$strains of Streptomyces we showed that physically detectable plasmids are not involved in the biosynthesis of this antibiotic (Ahmed \& Vining, 1983; Doull et al., 1983). To investigate further the genetic control of chloramphenicol biosynthesis in S. venezuelae ISP 5230 (the type strain of the species, also listed as ATCC 10712) we isolated and characterized 12 independent chloramphenicol-nonproducing $\left(\mathrm{Cml}^{-}\right)$mutants (Doull et al., 1985). Owing to a lack of conjugational fertility in genetically marked derivatives of $\mathrm{Cml}^{+}$and $\mathrm{Cml}^{-}$strains we were initially unable to confirm an earlier report that genes encoding enzymes in the chloramphenicol biosynthetic pathway had a chromosomal location in derivatives of strain ISP 5230 (Akagawa et al., 1975, 1979).

Since plasmid-determined conjugational fertility (detected as chromosomal gene recombination) is apparently widespread in Streptomyces, and recombinant frequencies are often higher when one parent in a cross lacks the fertility plasmid (plasmid-minus) while the other parent is plasmid-plus (Friend et al., 1978; Bibb \& Hopwood, 1981; Hopwood \& Chater, 1984), it seemed likely that such fertility might be obtainable in $S$. venezuelae, either by elimination of a physically undetected endogenous fertility plasmid, or by introduction of an exogenous plasmid. Fertility plasmids are not always physically detectable by standard procedures, but seem to be almost universally detectable through 'pock' formation or 'lethal zygosis' $\left(\mathrm{Ltz}^{+}\right)$(Bibb et al., 1981 ; Bibb \& Hopwood, 1981; Hopwood \& Chater, 1984). This phenotype is recognizable as a retardation of aerial mycelium growth (lethality being doubtful) and is observed after spores of a plasmid-plus $\left(\mathrm{Ltz}^{+}\right)$strain are spotted or replicated on a lawn of spores of a plasmid-minus ('lethal-zygosis-sensitive', Ltz's) indicator strain (Bibb et al., 1981; Hopwood et al., 1983). Strains lacking plasmid are frequently isolated from among colonies of regenerated protoplasts

† Present address: Department of Microbiology, University of Edinburgh, West Mains Road, Edinburgh EH9 3JG, UK.

$\ddagger$ Present address: CIFT, Technical University of Nova Scotia, Halifax, Nova Scotia, Canada. 
(Hopwood, 1981; Hopwood et al., 1983), although they may also arise as spontaneous segregants in otherwise plasmid-plus spore populations (Friend et al., 1978). They may be detected either by their Ltz $\mathrm{z}^{\mathrm{s}}$ phenotype when tested with parental spores or by their enhanced fertility in plate crosses (Bibb et al., 1977; Friend et al., 1978).

In this paper we report the isolation of conjugationally fertile $\mathrm{Ltz}^{\mathrm{s}}$ derivatives of $S$. venezuelae strain ISP 5230 resulting from putative plasmid loss, and their use in the construction of a chromosomal linkage map that includes the $\mathrm{cml}$ loci defined by the mutations in our $12 \mathrm{Cml}^{-}$ mutants.

\section{METHODS}

Strains, growth conditions and genetic techniques. Genetically marked strains were isolated after mutagenesis of the parental prototrophic chloramphenicol-producing type strain of $S$. venezuelae, ISP 5230 (also listed as ATCC 10712) (Stuttard 1982; Doull et al., 1985). Auxotrophic mutants of SPI 5230 used in the present study are listed in Table 1. Gene designations are given to correspond with analogous loci in $S$. coelicolor, or to show differences, or are omitted when the phenotypic characterization is insufficient to define the gene. Agar media for growth of the bacteria have been described previously (Stuttard 1982; Doull et al., 1985). In conjugational crosses about $10^{6}$ spores (c.f.u.) of a putative plasmid-plus strain were spread together with an excess (usually 20-fold) of spores of a putative plasmidless strain on MYM agar to give approximately equal frequencies of parental-type spores among the progeny, so balancing the cross. Analysis of crosses was done by either the 'four-on-four' or the single-selection (allele-gradient) procedure of Hopwood (1967); these procedures are described in Hopwood et al. (1985). All incubations were at $30^{\circ} \mathrm{C}$.

In the 'four-on-four' procedure, spores from a mixed culture of two mutants differing at four loci were spread on four different types of selective agar plates on which parental-type spores would not grow. The phenotypes of a sample of recombinants appearing on each medium were determined by replication to diagnostic media which allowed the nine recoverable (of 14 possible) recombinant phenotypes (including two reciprocal pairs) to be identified. As Hopwood (1967, 1972; Hopwood et al., 1985) has pointed out, the validity of subsequent analysis depends upon the data satisfying two internal conditions: $(a)$ to exclude the possibility of bias against the growth of any recombinant with a particular phenotype, the frequency (c.f.u. per unit volume of progeny spores at a standard dilution) of each recombinant type should be about the same on at least two of the four selective media; $(b)$ both members of the two pairs of complementary genotypes that can be recovered should arise at approximately equal frequencies to indicate statistically equal (non-polarized) contributions by the two parents to the recombinant genomes. If there were greater than fivefold differences in any of these internal checks the data were not used in our analysis.

When the relative locations of selective markers had been established on a circular map in 'four-on-four' crosses, the location of any $\mathrm{cml}$ marker present was then determined as follows. Recombinant progeny from crosses between chloramphenicol-producing and non-producing mutants were picked from selective plates and restreaked on MYM agar to obtain single colonies. After sporulation, single colonies were patched on fresh selective agar, grown to sporulation and replicated to diagnostic media for marker verification. Inocula were then taken from each master patch and tested for chloramphenicol production by bioassay (see below).

When pairs of mutually fertile strains with five or six different markers of known relative locations were available, a new marker in either strain could be located by the 'allele-gradient' procedure (Hopwood, 1967, 1972; Hopwood et al., 1985): two well-separated markers, one from each parent, were chosen as selective markers, all others being non-selective. Recombinants obtained from the cross after plating progeny spores on a selective medium were phenotypically characterized as in 'four-on-four' crosses. The frequency of each member of each pair of unselected alleles in the cross was then estimated. These 'allele ratios' formed clockwise and anticlockwise gradients on either side of each selective marker: parental-type alleles close to the selected parental marker were more frequent in recombinants than those further away. The allele ratio of the new marker was used to locate that marker in either the clockwise or anticlock wise gradient. The final position chosen was that which minimized the number of multiple cross-over progeny from the cross.

Isolation of fertility variants. The technique used initially was essentially that of Hopwood et al. (1983). Protoplast regenerants of auxotrophically-marked strains were patched to MYM, spotted with spores of their parental strain, incubated for 3-5d, and then screened for a 'lethal-zygosis' $\left(\mathrm{Ltz}^{\mathrm{s}}\right)$ response. Subsequent screenings were done with patches made directly from single colonies grown on MYM or supplemented minimal agar from various spore suspensions (either individual stock cultures or individual progeny from crosses). Putative plasmid-minus isolates were then tested for fertility (chromosomal gene recombination) in plate crosses with a differently marked ' $\mathrm{Ltz}^{+}$' strain. The parental ' $\mathrm{Ltz}^{+}{ }^{\prime}$ strain was used as a control on the same plates (Friend et al., 1978).

Screening.for chloramphenicol production. Spores from the colonies to be tested were spread in patches in MYM agar (five equally spaced patches per $85 \mathrm{~mm}$ diameter plate). The patched colonies were grown for $48-72 \mathrm{~h}$; the 
Table 1. Streptomyces venezuelae strains

VS Strain

no.

65

88

98

113

130

141

143

146

153

160

161

162

166

191

192

194

206

227

230

237

242

246

251

253

263

296

297

300

304

305

306

310
Chromosomal markers*

his-6

met $A 8$

arg-6 $\mathrm{cml}-4$

his- 6 ade $A 10$

cys $B 13 \mathrm{cml}-4$

lys $A 7 \mathrm{cml}-1$

metBl $4 \mathrm{cml}-7$

nic B6 $\mathrm{cml}-7$

trp-3 cml-5

uraAl thrCl trp-5

uraAl thrCl tyr-2

uraAl thrCl ilv-5

uraAl Iys $A \mid$

his- 6 ade $A 10$

his-6 ade $A 10$

his- 6 ade $A 10$

his-6 ade 110 str A6

uraB5 $\mathrm{cml}-2$

proAl $\mathrm{cml}-6$

l) $\mathrm{sA} 10 \mathrm{cml}-6$

rib-2 $\mathrm{cml}-6$

phe $46 \mathrm{~cm} /-11$

nic $B 8 \mathrm{cml}-11$

pd $x B 3 \mathrm{~cm} /-11$

cys- $28 \mathrm{cml}-12$

adeA 10 uraAl thrCl trp-5 strA6 rifA3

metA 8 str $A 6$

ade $A 10$ tyr-2 str $A 6$

arg- 6

ade 10 uraAl thrCl ilv-5 strA6

uraAl thrCl ilv-5

ade $A 10$ cysB13 strA6
Source $\nmid$ or reference

Stuttard (1983b)

Spontaneous reversion of his-5 in a double mutant

(VS104) (C. Stuttard, unpublished data)

Cml-4 (MOP)

vS65 (MOP)

$\mathrm{Cml}-4$ (MOP)

Stuttard (1983a)

Cml-7 (UV, Z. Ahmed)

Cml-7 (MOP, Z. Ahmed)

Stuttard (1983b)

VS83 (Stuttard, 1983a) by UV mutagenesis

(Z. Ahmed)

VS83 (UV, Z. Ahmed)

VS83 (UV, Z. Ahmed)

Transduction VS83( $\times$ )VSI (Stuttard, 1983a)

This paper

This paper

This paper

Spontaneous, from VS191

$\mathrm{Cml}-2$

Cml-6

Cml-6

Cml-6

Cml-11

Cml-11

Cml-11

Cml-12

Spontaneous Rif ${ }^{\mathrm{R}}$ mutant of VS294, a

recombinant from VS206 $\times$ VS160

' $\mathrm{Ltz}^{-}$' recombinant from VS206 $\times$VS88

' $\mathrm{Ltz}^{-'}$ recombinant from VS206 $\times$ VS161

' $\mathrm{Ltz}^{-}$' recombinant from VS300 $\times$VS98

Recombinant from VS206 $\times$ VS162

${ }^{\prime} \mathrm{Ltz}^{-}$recombinant from VS206 $\times$VS162

Recombinant from VS206 $\times$ VS130

* Gross phenotypes of single auxotrophs as in Hopwood et al. (1985), except that $p d x B$ gave a requirement for pyridoxal rather than pyridoxine: $c y s-28$ gave a $c y s E$ phenotype.

+ Source strains were mutagenized with EMS (ethylmethane sulphonate) unless otherwise indicated: MOP, 8methoxypsoralen plus near UV; UV, ultraviolet light, $256 \mathrm{~nm} . \mathrm{Cml}^{-}$mutants are described in Doull et al. (1985).

plates were then carefully overlaid between the patches with soft $(0.5 \%$, w/v) GNY agar seeded with Micrococcus luteus. The overlaid plates were incubated overnight and inhibition zones were examined. Wild-type chloramphenicol producers gave a clear zone extending about $10-15 \mathrm{~mm}$ from the edge of the patch.

\section{RESULTS}

Evidence for three conjugative plasmids in $S$. venezuelae

The doubly auxotrophic strain VS113 (his-6 adeA10) was tested for the occurrence of $\mathrm{Ltz}^{\mathrm{s}}$ variants after protoplast formation and regeneration. Of 100 regenerants spotted with a suspension of VS113 spores $\left(10^{7}\right.$ c.f.u. $\left.\mathrm{ml}^{-1}\right)$, two patches showed zones of aerial mycelium growth retardation at the periphery of the VS113 spot. These zones were phenotypically different (Fig. 1): a more distinct zone (viewed by transmitted light) was elicited on the regenerant designated VS191, and a less distinct zone on VS192. Similar, reciprocal Ltz tests between VS191 and VS192 showed that each elicited a different retardation zone when spotted on a patch of the other, but not on themselves or on the parent, VS113. A further variant, VS194, was isolated from strain VS191 after protoplast formation, regeneration and Ltz testing. Zones 


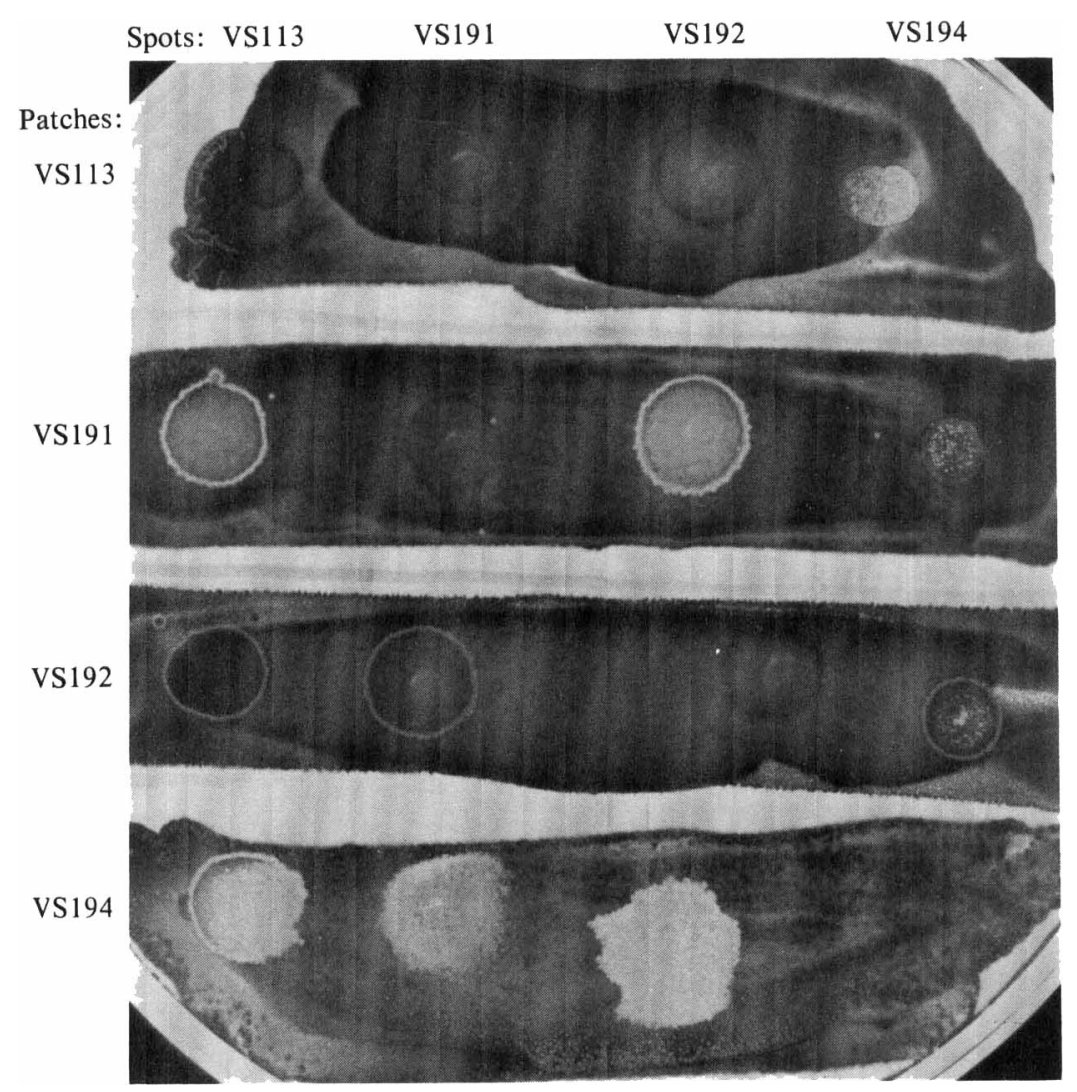

Fig. 1. Test for 'lethal zygosis' (light areas in or around spots) among derivatives of strain VS113, viewed by transmitted light.

of aerial mycelium growth retardation were elicited on patches of strain VS194 by spores of VS113 and the related strains VS191 and VS192. In addition, strain VS194 elicited a faint Ltz ${ }^{+}$ response on VS192 but not on VS191 or VS113. The derivations and Ltz responses of VS113 and its variants, and their interpretation using putative conjugative plasmid effects are given in Fig. 2. The proposed interpretation is based on that given by Hopwood et al. (1983) for similar results obtained with $S$. lividans. Thus, it would appear that there are at least three different conjugative plasmids in strain VS113 (and presumably in its parent strain ISP 5230). Although none of these was physically demonstrable by standard techniques (Doull et al., 1983; Ahmed \& Vining, 1983), in conjugational crosses involving VS191 or other Ltz ${ }^{\mathrm{s}}$ strains (see below) more than $90 \%$ of recombinant progeny, and $78-97 \%$ of progeny with the chromosomal genotype of the Ltz parent, were converted to an $\mathrm{Ltz}^{+} \mathrm{Ltz}^{\mathrm{R}}$ phenotype (Table 2). The results were consistent with high-frequency transfer of fertility plasmids. In conformity with established nomenclature for similar fertility plasmids in other streptomycetes, we propose to call these plasmids SVP1, SVP2, and SVP3 (Fig. 2).

The possibility that ' $L t z^{\mathrm{s}}$ ' segregants might arise spontaneously rather than through the process of protoplast formation and regeneration was investigated by screening 100 single colonies of each of several different auxotrophic derivatives of the wild-type strain of ISP 5230 . Of the eight spore stocks examined, five (including VS113) showed 1-2\% 'Ltz's' variants, mostly of the VS192 type (SVP3-). Therefore, it is likely that protoplast formation and regeneration were not essential for the recovery of VS191 and VS192 from VS113, although elimination of SVP2 (to give VS194) may have required this treatment. 


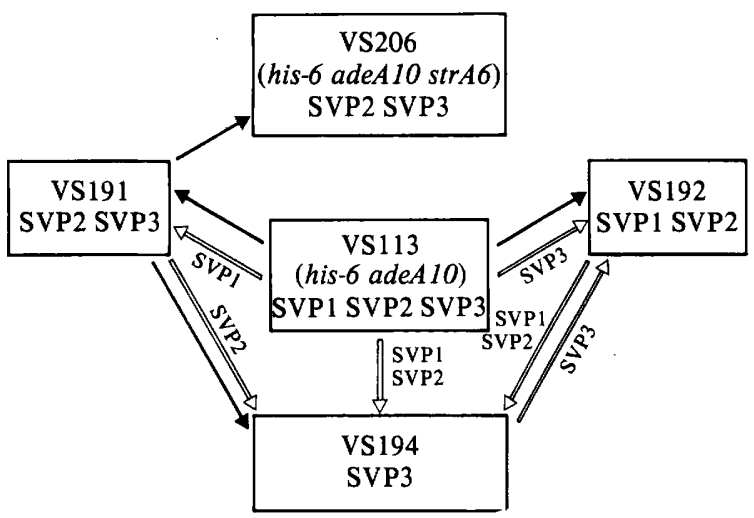

Fig. 2. Putative plasmid content and 'Ltz' responses of VS113 and its derivatives. Solid arrows indicate strain derivations by plasmid loss or, for VS206, by spontaneous mutation. Open arrows indicate 'lethal zygosis' elicited by the designated plasmid(s) in the plasmid-plus strain on contact with the corresponding plasmid-minus mycelium.

Table 2. Effects of plasmid on chromosomal gene recombination, and evidence for 'infectious' transfer of plasmid SVP1 in 'four-on-four' crosses involving strain VS113 (his-6 ade10) and its putative plasmid-minus derivatives

\author{
Parental strains* \\ (and plasmid deficiences)
}

VS113 $\times$ VS166

VS191 $\left(\right.$ SVP1 $\left.^{-}\right) \times$VS166

VS192 (SVP3-) $\times$ VS166

VS194 (SVP1-SVP2-) $\times$ VS166

VS206 $\left(\mathrm{SVP1}^{-}\right) \times \mathrm{VS} 88$

VS206 $\left(\mathrm{SVP1}^{-}\right) \times \mathrm{VS} 98$

VS206 $\left(\mathrm{SVP1}^{-}\right) \times \mathrm{VS} 161$

VS300 $\left(\mathrm{SVP1}^{-}\right) \times \mathrm{VS} 98$
Recombinant frequency $\dagger$ (per total progeny c.f.u.)

$<10^{-7}$
$10^{-4}$

$10^{-6}$
$2.5 \times 10^{-4}$
$10^{-4}$
$10^{-4}$
$10^{-4}$
$10^{-4}$

\begin{tabular}{crc}
\multicolumn{3}{c}{ Progeny tested } \\
$\overbrace{\text { Type } \ddagger}$ & No. & $\%$ SVP1- \\
- & 0 & - \\
VS166 & 146 & $<1$ \\
VS191 & 50 & 22 \\
Rec & 483 & 1 \\
- & 0 & - \\
- & 0 & - \\
Rec & 289 & 3.5 \\
Rec & 493 & 5 \\
Rec & 305 & 7.5 \\
VS300 & 190 & 2.6 \\
VS98 & 239 & 0.8
\end{tabular}

* See Table 1 for genotypes and Fig. 2 for plasmids; plasmid-plus parental spores were mixed with a 20-fold excess of plasmid-minus parental spores to give approximately equal frequencies of parental-type c.f.u. in the progeny from each cross on MYM.

† Recombinant totals were obtained from the four different selective agar plates; c.f.u. were counted on MYM. Reversion frequencies for each marker in all crosses were in the range $10^{-7}-10^{-9}$ per c.f.u.

¥ Strain designations indicate parental-type progeny; Rec, recombinant progeny of all selected genotypes.

When strains VS113, VS191 (SVP1-), VS192 (SVP3-) and VS194 (SVP1-SVP2-) were tested for chloramphenicol production after growth for $7 \mathrm{~d}$ in production medium (Doull et al., 1985) the concentrations obtained were approximately $170,130,130$, and $120 \mathrm{~g} \mathrm{ml}^{-1}$, respectively. Thus loss of none of the plasmids had any significant effect on chloramphenicol biosynthesis.

The relative fertilities of strain VS113 and its derivatives were tested simultaneously in a plate cross with strain VS160 ( $u$ raAl thrCl trp-5). The result (not shown) was that VS191 and VS194 gave similar frequencies of recombinant colonies, and these were visibly higher than that given by VS192, while VS113 gave no recombinants with VS160 in this test. Therefore, it appeared that SVP1 had a major role in recombinant formation and functioned like SCP2 and SLP2 in $S$. lividans 66 (Hopwood et al., 1983), or SRP1 in S. rimosus (Friend et al., 1978). Likewise, SVP3 mediated recombination but at a much lower frequency than SVP1. More precise estimates of 
Table 3. Analysis of the four-factor cross VS206 (his-6 adeA10 strA6) $\times$ VS237 (lysA10 cml-6)

Frequencies of genotypes on selective media supplemented with:

\begin{tabular}{|c|c|c|c|c|c|c|c|c|c|c|c|c|}
\hline \multirow{2}{*}{\multicolumn{4}{|c|}{$\begin{array}{l}\text { Genotypes of } \\
\text { selectable progeny }\end{array}$}} & \multicolumn{2}{|c|}{ Histidine } & \multicolumn{2}{|c|}{ Adenine } & \multicolumn{2}{|c|}{$\begin{array}{l}\text { Histidine } \\
\text { Lysine } \\
\text { Streptomycin }\end{array}$} & \multicolumn{2}{|c|}{$\begin{array}{c}\text { Adenine } \\
\text { Lysine } \\
\text { Streptomycin }\end{array}$} & \multirow{2}{*}{$\begin{array}{c}\text { Mean } \\
\text { frequency of } \\
\text { each pair of } \\
\text { complementary } \\
\text { genotypes* }\end{array}$} \\
\hline & & & & $a$ & $b$ & $a$ & $b$ & $a$ & $b$ & $a$ & $b$ & \\
\hline+ & + & + & str & 24 & 30 & 14 & 20 & 42 & 35 & 40 & 50 & 33 \\
\hline+ & + & + & + & 166 & 240 & 126 & 200 & - & - & - & - & 220 \\
\hline his & + & + & str & 4 & 10 & - & - & 6 & 5 & - & - & $7 \cdot 5$ \\
\hline+ & ade & + & str & - & - & 61 & 100 & - & - & 47 & 60 & 80 \\
\hline+ & + & lys & str & - & - & - & - & 155 & 130 & 55 & 70 & 100 \\
\hline his & + & + & + & 20 & 30 & - & - & - & - & - & - & 55 \\
\hline+ & ade & lys & str & - & - & - & - & - & - & 66 & $80\}$ & 55 \\
\hline+ & ade & + & + & - & - & 0 & 0 & - & - & - & - & 0 \\
\hline his & + & lys & str & - & - & - & - & 0 & 0 & - & - & 0 \\
\hline \multicolumn{4}{|c|}{ Sample size: } & 214 & & 201 & & 203 & & 208 & & \\
\hline \multicolumn{4}{|c|}{$\begin{array}{l}\text { Total recombinants } \\
\text { per unit volume: }\end{array}$} & & 310 & & 320 & & 170 & & 260 & \\
\hline
\end{tabular}

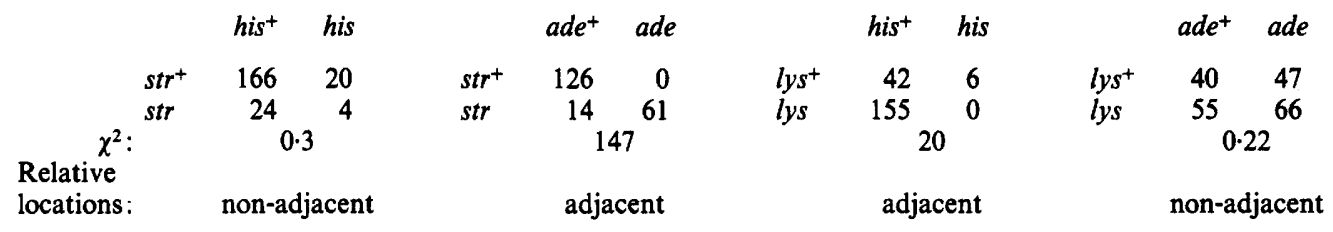

Relative recombination frequencies in each interval $\ddagger$

$\begin{array}{cccccc}\text { his-lys } & \text { lys-str } & \text { str-ade } & \text { ade-his } & \text { his-str } & \text { lys-ade } \\ 333 & 375 & 140.5 & 142.5 & 268 & 315.5\end{array}$

* From ' $b$ ' columns.

+ From ' $a$ ' columns.

$\ddagger$ Calculated from the mean frequencies of each pair of complementary genotypes, last column in main table.

recombination frequencies were obtained from crosses between various differentially marked plasmid-plus mutants and VS113 (SVP1+SVP2+SVP3+), VS191 (SVP1 $\left.{ }^{-}\right)$, VS192 $\left(\right.$SVP3 $\left.^{-}\right)$or VS194 (SVP1-SVP2-) (Table 2).

\section{A chromosomal linkage map for $S$. venezuelae}

With the isolation of the conjugationally fertile strain VS191 and a spontaneous streptomycinresistant mutant of it, VS206 (his-6 adeA10 strA6), we were able to use the 'four-on-four' procedure of Hopwood (see Methods) to generate a preliminary linkage map of auxotrophic and drug-resistance markers in $S$. venezuelae. An example of a 'four-on-four' analysis is given in Table 3 and Fig. 3.

Fifteen 'four-on-four' crosses were analysed to find the locations of 16 auxotrophic markers relative to his6, ade10 and strA6. In most of these crosses one parent was also defective in chloramphenicol production $\left(\mathrm{Cml}^{-}\right)$. Therefore, each $\mathrm{cml}$ mutation was mapped as a nonselective marker by determining the distribution of $\mathrm{Cml}^{+}$and $\mathrm{Cml}^{-}$types within each class of recombinants, using the bioassay test (see Methods). An example of this analysis, for the cross VS206 $\times$ VS237, is given in Table 4, where the most probable arrangement of selective markers has been established in the previous analysis and the choice of location for the $\mathrm{cml}$ marker is again based on minimizing the number of crossovers required to give each recombinant type. The conclusion drawn from 'four-on-four' crosses between VS206 $\left(\mathrm{Cml}^{+}\right)$and various $\mathrm{Cml}^{-}$ auxotrophs (Table 5) is that the $\mathrm{cml}$ mutations $-1,-2,-5,-6,-7,-11$ and -12 are all located in the 


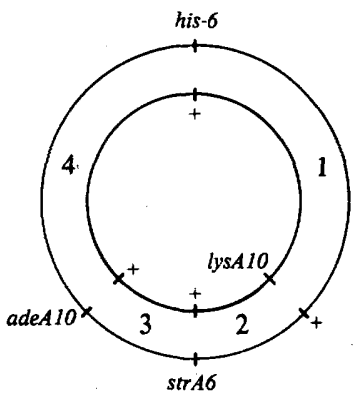

A

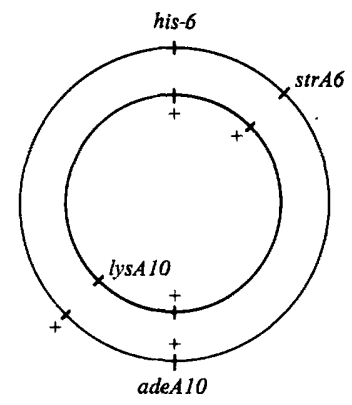

B

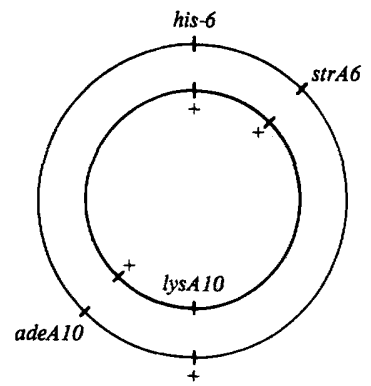

C

3

Frequency: 0

$5 \cdot 5$

Fig. 3. Alternative arrangements of markers in the cross VS206 $\times$ VS237. The frequencies shown are the mean relative frequency of reciprocal recombinants requiring quadruple crossovers.

Table 4. Chloramphenicol production in recombinant progeny from cross VS206 (his-6 adeA10 strA6) $\times$ VS237 (lys A10 cml-6)

Recombinants

\begin{tabular}{|c|c|c|c|c|c|c|c|}
\hline \multicolumn{4}{|c|}{ Genotype } & $\begin{array}{c}\text { Mean } \\
\text { frequency* }\end{array}$ & $\begin{array}{l}\text { No. } \\
\text { tested }\end{array}$ & $\% \mathrm{cml}^{+}$ & $\begin{array}{l}\text { Inferred location of } \\
\mathrm{cml}-6 \text { (see Fig. } 5 \text { ) }\end{array}$ \\
\hline+ & + & + & str & 33 & 70 & $2 \cdot 8$ & Not between his and adeA \\
\hline+ & + & + & + & 220 & 70 & 0 & Not between ade $A$ and $\operatorname{str} A$ \\
\hline his & + & + & str & $7 \cdot 5$ & 20 & 100 & Between his and lys $A$ or $l y s A$ and $\operatorname{str} A$ \\
\hline+ & ade & + & str & 80 & 70 & 8.5 & Not between adeA and lys $A$ \\
\hline+ & + & lys & str & 100 & 70 & 0 & $\begin{array}{l}\text { Not near strA, possibly between his } \\
\text { and lys }\end{array}$ \\
\hline+ & ade & lys & str & 80 & 45 & 0 & Not between ade $A$ and $s t r A$ \\
\hline his & + & + & + & 30 & 4 & 100 & Not near str $A$ \\
\hline
\end{tabular}

Conclusion: the most likely location of $\mathrm{cml}-6$ is between his and lys $A$.

* Number of colonies per $0.1 \mathrm{ml}$ of spore suspension diluted $10^{-2}$ and spread on selective media.

Table 5. Conclusions from 'four-on-four' crosses mostly between the $\mathrm{Cml}^{+}$strain VS206 (his-6 ade $\mathrm{AlO}$ strA6) and $\mathrm{Cml}^{-}$parents bearing single auxotrophic markers

$\mathrm{Cml}^{-}$Parent

$\overbrace{\text { Strain no. }}^{\text {Genotype }}$

VS98†

VS130†

VS141

VS143

VS146

VS153

VS166tt

VS227

VS230

VS237

VS242

VS246

VS251

VS253

VS 263 arg- $6 \mathrm{cml}-4$ cys $B 13 \mathrm{cml}-4$ lys $A 7 \mathrm{cml}-1$ met $B 14 \mathrm{cml}-7$ nic $B 6 \mathrm{cml}-7$ trp-3 cml-5 uraAl lysAl uraB5 $\mathrm{cml}-2$ proAl $1 \mathrm{cml}-6$ lys $10 \mathrm{cml}-6$ rib-2 cml-6 phe $A 6 \mathrm{cml}-1 \mathrm{l}$ nic $B 8 \mathrm{cml}-11$ pdx $B 3 \mathrm{cml}-11$ cys-28 cml-12
Relative locations* of

$\overbrace{\text { Selective markers }}^{\mathrm{cml} \text { mutations }}$

arg- 6 between his 6 and str $A 6$

cys $B 13$ between ade $A 10$ and $\operatorname{str} A 6$

lys $A 7$ as arg- 6

met $B 14$ as cys $B 13$

nic $B 6$ between his- 6 and ade $A 10$

trp-3 very near his-6

ura $A l$ between his-6 and strA6, opposite $l y s A I$

uraB5 as arg-6

pro $A l$ as nicB6

lys $A 10$ as $\arg -6$

rib-2 as arg-6

phe $A 6$ as nicB6

nicB8 as nicB6

$p d x B 3$ as arg-6

cys-28 as arg-6

$\mathrm{cml}-\mathrm{l}$ between his- 6 and $l y s A 7$

$\mathrm{cml}-7$ between his- 6 and strA6

cml-5 between $\operatorname{trp}-3$ and $s t r A 6$

$\mathrm{cml}-2$ near $\mathrm{uraB} 5$

$\mathrm{cml}-6$ between his- 6 and str $A 6$ $\mathrm{cml}-6$ between his- 6 and $l y s A 10$ cml-6 near rib-2

$\mathrm{cml}-11$ between his6 and strA6

cml-12 near cys-28

* On a circular linkage map.

$\dagger$ Both parents in the cross were $\mathrm{Cml}^{+}$.

‡ VS166 was crossed with VS191 (his-6 adeA10). 

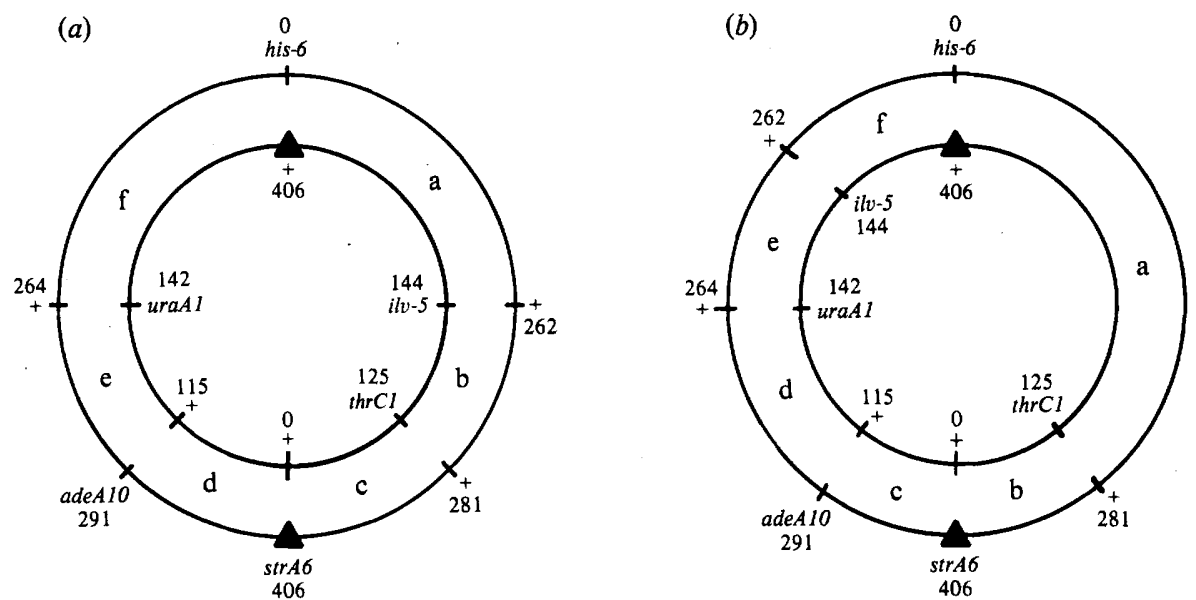

Fig. 4. Alternative locations of $i l v-5$ in the cross VS206 $\times$ VS162.

Table 6. Mapping ilv-5 by single selection $\left(\mathrm{His}^{+} \mathrm{Str}^{\mathrm{R}}\right)$

Cross: VS206 (his-6 ade10 strA6) $\times$. VS162 (uraAl thrC1 ilv-5)

Genotypes of selectable recombinants*

\begin{tabular}{|c|c|c|c|}
\hline ade $A 10$ & + & + & + \\
\hline+ & uraAl & + & + \\
\hline+ & + & $t h r C l$ & + \\
\hline+ & + & + & $i l v-5$ \\
\hline ade $A 10$ & uraAl & + & + \\
\hline ade $A 10$ & + & $\operatorname{thr} C l$ & + \\
\hline adeA10 & + & + & $i l v-5$ \\
\hline+ & uraAl & $\operatorname{thr} C 1$ & + \\
\hline+ & uraAI & + & $i l v-5$ \\
\hline+ & + & $\operatorname{thr} C 1$ & $i l v-5$ \\
\hline ade $A 10$ & uraAl & $t h r C l$ & + \\
\hline adeA10 & + & $t h r C l$ & $i l v-5$ \\
\hline ade $A 10$ & uraAl & + & $i l v-5$ \\
\hline+ & uraAl & $t h r C l$ & $i l v-5$ \\
\hline ade $A 10$ & uraAl & $t h r C l$ & $i l v-5$ \\
\hline+ & + & + & + \\
\hline
\end{tabular}

Numbers of:

\begin{tabular}{|c|c|c|}
\hline \multirow{4}{*}{$\begin{array}{l}\text { Recombinant } \\
\text { progeny } \\
220\end{array}$} & \multicolumn{2}{|c|}{ Crossovers required $\dagger$} \\
\hline & & \\
\hline & $a$ & $b$ \\
\hline & 2 & 2 \\
\hline 20 & 2 & 4 \\
\hline 0 & 6 & 4 \\
\hline 1 & 4 & 4 \\
\hline 15 & 2 & 4 \\
\hline 0 & 4 & 2 \\
\hline 9 & 2 & 2 \\
\hline 2 & 4 & 4 \\
\hline 10 & 2 & 2 \\
\hline 4 & 4 & 4 \\
\hline 0 & 4 & 4 \\
\hline 25 & 2 & \\
\hline 1 & 2 & 2 \\
\hline 73 & 2 & 2 \\
\hline 21 & 2 & 2 \\
\hline 5 & 4 & 4 \\
\hline
\end{tabular}

Total: $\quad 406$

Total recombinants requiring 4 or 6 crossovers:

* Selective markers are omitted.

$\dagger$ Alternative arrangements of markers: $a$, ilv-5 between his- 6 and $t h r C l ; b$, ilv-5 between his- 6 and uraAl (see Fig. 4).

same region of the $S$. venezuelae linkage map between his-6 and lys $A$. In particular, markers $\mathrm{cml}-2,-6$ and -12 are near markers that, by analogy with $S$. coelicolor, are probably in the 1-2 o'clock region of the linkage map.

\section{Mapping by single selection}

Multiply-marked strains bearing a new mutation together with mutations for which the relative order was known were used in further crosses. Each involved a single selection, with 


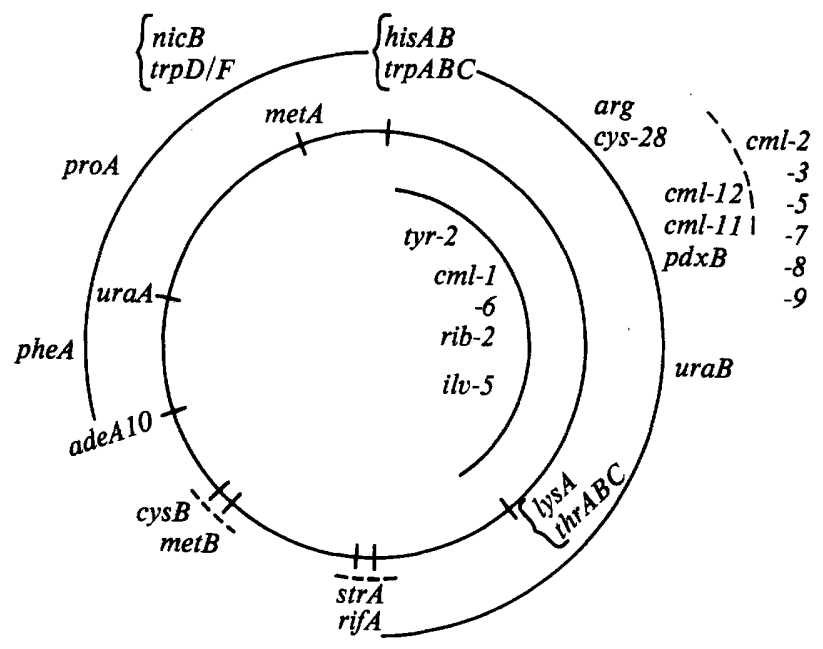

Fig. 5. Linkage map of $S$. venezuelae. Spacing between loci is arbitrary except that those previously shown to be cotransducible are bracketed together. Relative orders of markers shown on inner and outer arcs have not been determined.

Table 7. Location of auxotrophic markers by single selection (allele-gradient analysis)

Cross*
VS206 $\times$ VS161
VS206 $\times$ VS162
VS296 $\times$ VS297
VS304 $\times$ VS305
VS306 $\times$ VS310

Marker arrangement $\dagger$

tyr- 2 between $\operatorname{trp}-5$ and $t h r C l$ ilv-5 between his- 6 and $t h r C l$ met $A 8$ between $\operatorname{trp}-5$ and $u r a A l$ arg- 6 between $i l v-5$ and $u r a A l$ cysB 13 between ade $A 10$ and $\operatorname{str} A 6$

* See Table 1 for strain genotypes.

† On a circular linkage map; thrCI and trp-5 were previously located by cotransduction very close to $l y s A$ and his-6, respectively (Stuttard, 1983a, b).

recombinants subjected to an 'allele-gradient' analysis from which the location of the new mutation was deduced (Hopwood, 1967; Hopwood et al., 1985). Several crosses gave rise to putative heterokaryons (colonies giving no growth when spores were patched to fresh plates of the same selective agar) at frequencies of less than $5 \%$. Heterokaryons were not considered in the present analysis. An example of single-selection analysis is given in Table 6 and Fig. 4. The conclusions drawn from five such crosses (Table 7) are incorporated with data obtained by 'fouron-four' analyses in the conjugational linkage map of $S$. venezuelae shown in Fig. 5.

\section{DISCUSSION}

The present results obtained with $S$. venezuelae are directly analogous to similar observations of fertility in S. rimosus (Friend et al., 1978) and S. lividans 66 (Hopwood et al., 1983) in that one or more physically undetected self-transmissible genetic elements, presumably plasmids, are involved. Also, it is apparently the loss of plasmid that generates the subsequent fertility of the plasmid-minus strains in crosses with a strain that has retained the plasmid. The range of markers in plasmid-minus strains is presently too limited to permit comprehensive estimates of relative fertilities mediated by each of the plasmids SVP1, SVP2 and SVP3 alone, and strains that lack all three plasmids have yet to be isolated. However, the present studies suggest that SVP1 is the major fertility plasmid in $S$. venezuelae, while SVP3 mediates a considerably lower frequency of chromosomal recombination. The role of SVP2 in fertility is not clear from the 
present data, although it does seem to give a slight additive effect with SVP1 (compare the fertilities of VS191 and VS194 in Table 2).

The presence of all three plasmids in both parents in a mating mixture inhibited chromosomal recombination, but apparently did not block heterokaryon formation. Complementary plasmidplus auxotrophs inoculated close together in patches on minimal agar often gave rise to tufts of growth in regions where the two patches met. However, only parental-type spores (in approximately equal frequencies) were recovered from such growth (C. Stuttard, unpublished data). The fact that hyphal contact was essential for this effect suggests that crossfeeding was not involved. Hyphal fusion and consequent heterokaryon formation would allow genetic complementation to give the prototrophic growth phenotype. A similar phenomenon has been documented in S. coelicolor A3(2) (Micheli et al., 1984).

If, as seems likely, hyphal fusion and heterokaryon formation can occur in Streptomyces regardless of the plasmid status of parental strains, then the role of a 'fertility' plasmid may be in the activation of a chromosomal $r e c A$-type gene in the plasmid-minus host, thus facilitating chromosomal recombination within the heterokaryon. Alternatively, the plasmid may carry its own recA-type gene which becomes activated when the plasmid is introduced into a previously plasmidless cytoplasm. Obviously, the answers to these questions await the isolation of $\mathrm{Rec}^{-}$ strains.

In addition to establishing the presence of fertility factors in $S$. venezuelae, the present work complements our previous determination that plasmids are not involved in chloramphenicol biosynthesis (Ahmed \& Vining, 1983; Doull et al., 1983) by defining the chromosomal location of $\mathrm{cml}$ genes. Also, an association between the fertility factors and antibiotic production can be discounted from the fact that strains VS113, VS191, VS192 and VS194 all produce similar levels of chloramphenicol. Two previous studies (Francis et al., 1975; Akagawa et al., 1975) generated preliminary linkage maps of $S$. venezuelae strains $3022 \mathrm{a}(13 \mathrm{~s})$ and ISP 5230, respectively, but neither produced adequate data to locate $\mathrm{cml}$ mutations. In subsequent work, Akagawa et al. (1979) located $c p p(\mathrm{cml})$ markers between 'met' and 'ilv' on a linkage map of $S$. venezuelae ISP 5230 which included six other chromosomal markers. Assuming that the 'met' and 'ilv' loci were analogous to met $A 8$ and $i l v-5$ markers on the present map (Fig. 5), then the locations of $c p p$ and $\mathrm{cml}$ markers are mutually consistent. However, Akagawa et al. $(1975,1979)$ did not isolate discrete fertility variants, and did not use the conventional 'four-on-four' and single-selection analyses in their mapping. More particularly, the location of a ' $l y s$ ' marker between met and leu was deemed to be consistent with the similar location of a 'lys' marker on the S. coelicolor A3(2) linkage map. This is diametrically opposite to the location of ten independent lys mutations found in our present and previous work (Stuttard, $1983 a$; Fig. 5). There should be only one locus for uniquely lysineless mutations, namely lys $A$, which specifies the final enzyme in lysine biosynthesis, diaminopimelate decarboxylase (K. Wong \& C. Stuttard, unpublished data). Any other mutant defective in lysine biosynthesis through an earlier block in the lysine pathway should also require diaminopimelate for growth and would be characterized as a dap mutant. When the linkage maps of other Streptomyces species, including $S$. achromogenes (Coats \& Stroman, 1978) and $S$. rimosus (Rhodes et al., 1981), are aligned with the $S$. coelicolor A3(2) map each has a single lys locus in the same relative position as $l y s A$ in Fig. 5. The apparently discrepant location of $l y s A$ in $S$. coelicolor A3(2) may have resulted from misclassification of a leaky dap mutant which was not biochemically characterized (D. A. Hopwood, personal communication). The relative location of a pro marker on the map of Akagawa et al. (1979) also differs from pro on the present $S$. venezuelae map; only the latter is consistent with the location of a single pro locus in $S$. coelicolor as well as in $S$. lividans, $S$. glaucescens and $S$. rimosus. A reorientation of markers on the Akagawa map could make the arrangement of most loci, including $l y s$ and pro, consistent with the present map, but would place $c p p$ loci diametrically opposite to $\mathrm{cml}$, and would leave $s t r$ and ade in aberrant positions.

Since these discrepancies raise some doubts about the reliability of the unconventional mapping procedure used by Akagawa et al. $(1975,1979)$, we believe that the present data represent a more satisfactory determination of the chromosomal location of $\mathrm{cml}$ genes on a linkage map of $S$. venezuelae. This map is considerably more detailed than any previously 
available, and is (almost) entirely consistent with the arrangement of analogous (if not homologous) loci in $S$. coelicolor A3(2). This relationship has also been confirmed in cotransduction tests which show that adjacent markers in $S$. coelicolor have cotransducible analogues in S. venezuelae (Stuttard, $1983 b$; C. Stuttard, S. Vats \& L. Atkinson, unpublished data). Since most Streptomyces linkage maps of genes involved in primary metabolism are very similar (Hopwood et al., 1983), it is of interest to note that the relative locations of genes involved in secondary metabolism, especially the biosynthesis of different antibiotics, are quite varied. Thus in S. coelicolor A3(2), genes for the synthesis of three antibiotics, actinorhodin, a calciumdependent antibiotic and undecylprodigiosin, are located in three well-separated clusters (act, $c d a$ and red loci, respectively) (Hopwood et al., 1985). In $S$. rimosus there are two clusters of oxytetracycline genes in diametrically opposite locations at the 3 o'clock and 9 o'clock positions (Rhodes et al., 1981); and in S. erythreus the ery genes are at 7 to 8 o'clock (Weber et al., 1985). The location of $\mathrm{cml}$ genes between cys-28 and $p d x B$ (S. Vats and C. Stuttard, unpublished transduction data) at 1-2 o'clock on the $S$. venezuelae map is close to a possible location of aromatic pathway (aro) genes (by analogy with $S$. coelicolor). Therefore, it will be of interest to determine whether $\mathrm{cml}$ and aro genes are adjacent in $S$. venezuelae, and whether this proximity is involved in the regulatory switch between the primary and secondary metabolism of chorismic acid in $S$. venezuelae.

This work was supported by operating grants from the Medical Research Council of Canada and the National Science \& Engineering Research Council of Canada. Janice Doull was the recipient of an Izaak Walton Killam Memorial Scholarship. We thank Mary Dwyer for technical assistance, and Carolyn Murphy and Marie Richard for word-processing.

\section{REFERENCES}

AHMED, Z. U. \& VINING, L. C. (1983). Evidence for a chromosomal location of the genes coding for chloramphenicol production in Streptomyces venezuelae. Journal of Bacteriology 154, 239-244.

akagawa, H., Okanishi, M. \& Umezawa, H. (1975). A plasmid involved in chloramphenicol production in Streptomyces venezuelae: evidence from genetic mapping. Journal of General Microbiology 90, 336348.

Akagawa, H., Okanishi, M. \& UMeZaWa, H. (1979). Genetic and biochemical studies of chloramphenicol non-producing mutants of Streptomyces venezuelae carrying a plasmid. Journal of Antibiotics 32, 610620.

BiBB, M. J. \& Hopwood, D. A. (1981). Genetic studies of the fertility plasmid SCP2 and its SCP2* variants in Streptomyces coelicolor A3(2). Journal of General Microbiology 126, 427-442.

Bibb, M. J., Freeman, R. F. \& Hopwood, D. A. (1977). Physical and genetical characterization of second sex factor, SCP2, for Streptomyces coelicolor A3(2). Molecular and General Genetics 154, 155-166.

BibB, M. J., WARD, J. M., KiESER, T., COHEN, S. N. \& HOPWOOD, D. A. (1981). Excision of chromosomal DNA sequences from Streptomyces coelicolor forms a novel family of plasmids detectable in Streptomyces lividans. Molecular and General Genetics 184, 230240.

Coats, J. H. \& Stroman, D. W. (1978). Recent studies in Streptomyces achromogenes subsp. rubradiris genetics. In Genetics of the Actinomycetales, pp. 3946. Edited by E. Freerksen, I. Tarnok \& J. H. Thumin. Stuttgart: Gustav Fischer Verlag.
Doull, J., Vining, L. C. \& Stuttard, C. (1983). A cryptic plasmid in the chloramphenicol-producing actinomycete, Streptomyces phaeochromogenes. FEMS Microbiology Letters 16, 349-352.

Doull, J., Ahmed, Z., StuttaRd, C. \& Vining, L. C. (1985). Isolation and characterization of Streptomyces venezuelae mutants blocked in chloramphenicol biosynthesis. Journal of General Microbiology 131, 97-104.

Francis, M. M., Cella, R. L. \& Vining, L. C. (1975). Genetic recombination in a chloramphenicol-producing strain of Streptomyces species 3022a. Canadian Journal of Microbiology 21, 1151-1159.

Friend, E. J. WarReN, M. \& HopwoOd, D. A. (1978). Genetic evidence for a plasmid controlling fertility in an industrial strain of Streptomyces rimosus. Journal of General Microbiology 106, 201-206.

HoPwood, D. A. (1967). Genetic analysis and genome structure in Streptomyces coelicolor. Bacteriological Reviews 31, 373-403.

Hopwood, D. A. (1972). Genetic analysis in microorganisms. Methods in Microbiology 7B, 29-159.

HopwOOD, D. A. (1981). Uses of protoplasts in the genetic manipulation of streptomycetes. Zentralblatt für Bacteriologie Suppl. 11, 523-531.

Hopwood, D. A. \& Chater, K. F. (1984). Streptomyces. In Genetics and Breeding of Industrial Microorganisms, pp. 7-42. Edited by C. Ball. Boca Raton, Florida: CRC Press.

HOPWOOD, D. A., KIESER, T., WRIGHT, H. M. \& BIBB, M. J. (1983). Plasmids, recombination and chromosome mapping in Streptomyces lividans 66. Journal of General Microbiology 129, 2257-2269. 
Hopwood, D. A., Bibb, M. J., Chater, K. F., Kieser, T., Bruton, C. J., Kieser, H. M., Lydiate, D. J., SMith, C. P., WARD, J. M. \& SCHREMPF, H. (1985). Genetic Manipulation of Streptomyces. A Laboratory Manual. Norwich: John Innes Foundation.

Micheli, M., Semonti, G. \& Lanfaloni, L. (1984). Evidence of heterokaryosis in Streptomyces coelicolor A3(2). Molecular and General Genetics 194, 541-544.

Rhodes, P. M., Winskill, N., Friend, E. J. \& Warren, M. (1981). Biochemical and genetic characterization of Streptomyces rimosus mutants impaired in oxytetracycline biosynthesis. Journal of General Microbiology 124, 329-338.

STUTTARD, C. (1982). Temperate phages of Strepto- myces venezuelae: lysogeny and host specificity shown by phages SV1 and SV2. Journal of General Microbiology 128, 115-121.

STUTTARD, C. (1983a). Localized hydroxylamine mutagenesis, and cotransduction of threonine and lysine genes, in Streptomyces venezuelae. Journal of Bacteriology 155, 1219-1223.

STUTTARD, C. (1983b). Cotransduction of his and trp loci by phage SV1 in Streptomyces venezuelae. FEMS Microbiology Letters 20, 467-470.

Weber, J. M., WiERMAN, C. K. \& Hutchinson, C. R. (1985). A genetic analysis of erythromycin production in Streptomyces erythreus. Journal of Bacteriology 164, 425-433. 